\title{
Losses in the Nigerian Distribution Systems: A review of classification and strategies for mitigation
}

\author{
Orovwode Hope $^{1 *}$, Matthew Simeon ${ }^{2}$, Amuta, Elizabeth ${ }^{1}$, Alashiri, Olaitan ${ }^{1}$ \\ ${ }^{I}$ Electrical and Information Engineering Department, Covenant University Ota, Nigeria. \\ ${ }^{2}$ Electrical and Electronics Engineering Department, Federal University of Agriculture, Abeokuta, Nigeria.
}

\begin{abstract}
Power Distribution systems are prone to losses, be it technical or non-technical. These losses affect the efficiency, revenue, and expansion capacity of the system among others. The losses are mitigate-able though cannot be eliminated. In the case of the Nigerian distribution systems, these losses are abnormally high with detrimental consequences on the effective operation of the system. Thus this study is aimed at classifying and suggesting possible mitigation strategies for minimizing losses in the Nigerian distribution network.
\end{abstract}

Keywords: power distribution systems, technical losses, nontechnical losses, mitigation strategy

\section{INTRODUCTION}

The central electrical power network operated in most parts of the world today is made up of three sections, namely: generation, transmission, and distribution [1]. The distribution section of the network is directly in touch with the consumers as it steps down and distributes the energy at the required voltage to the consumers and thus subject to criticism of the consumers [1], [2]. As such the assessment of the quality of every central power system is determined by the quality of service delivery to the consumers by the distribution section.

With the privatization of the generation and distribution sections of the Nigerian power system in 2013 resulting in the emergence of eleven privately-owned distribution companies (DISCOs), there were lots of expectations that Nigeria was going to experience turn around in the sector [3]. However, the sector is still heavily plagued with several issues including the controversial energy charges, low power quality, and expansion capability, inability to make prepaid meters available to the consumers, frequent outages, and high technical and non-technical losses among others [4]. High technical and non-technical losses seem to be the worst of all the plagues as they have direct effects on energy charges, revenue generation, capacity for expansion, etc. As a result, there is an urgent need to develop strategies for mitigation of technical and non-technical losses in the Nigerian distribution systems. But before any meaningful strategy could be developed to mitigate the losses, the losses have to be identified and classified, thus this study is aimed at identifying, classifying and developing strategies for mitigating losses in the Nigerian distribution system

\section{LOSSES IN THE NIGERIAN DISTRIBUTION SYSTEMS}

In every electrical power network, losses are unavoidable and cannot be eliminated [2], [5]. They have remained one of the biggest challenges faced in electrical power systems operation with detrimental effects on the efficiency and income generation at all levels of the power network [6]. As a result, they must be kept at a low value as possible.

The distribution section, being more complex than the other sections of the power system is worst hit by losses [7]. Losses at the distribution section are the amounts of energy received from the transmission section by the distribution section but not paid for by the consumers. These losses are technically called Aggregate Technical, Commercial, and Collection (ATC \& C) losses.

ATC \& C losses were one of the reasons for the privatization of the Nigerian DISCOs. However, information from the NERC dataset showed that all the DISCOs are far from achieving the set target for ATC \& $\mathrm{C}$ loss reduction. For space constraint, only the ATC \& C losses data for Ikeja Electricity distribution is presented in this study as shown in figure 1 . Note that the Ikeja Electricity Distribution Company represented has the least ATC \& C losses after Eko Electricity Distribution Company when compared to the other DISCOs. To further show that that ATC \& C for the all the DISCOs are very high, the ATC \& C losses for all the DISCOs for February 2019 is presented in Table 1 


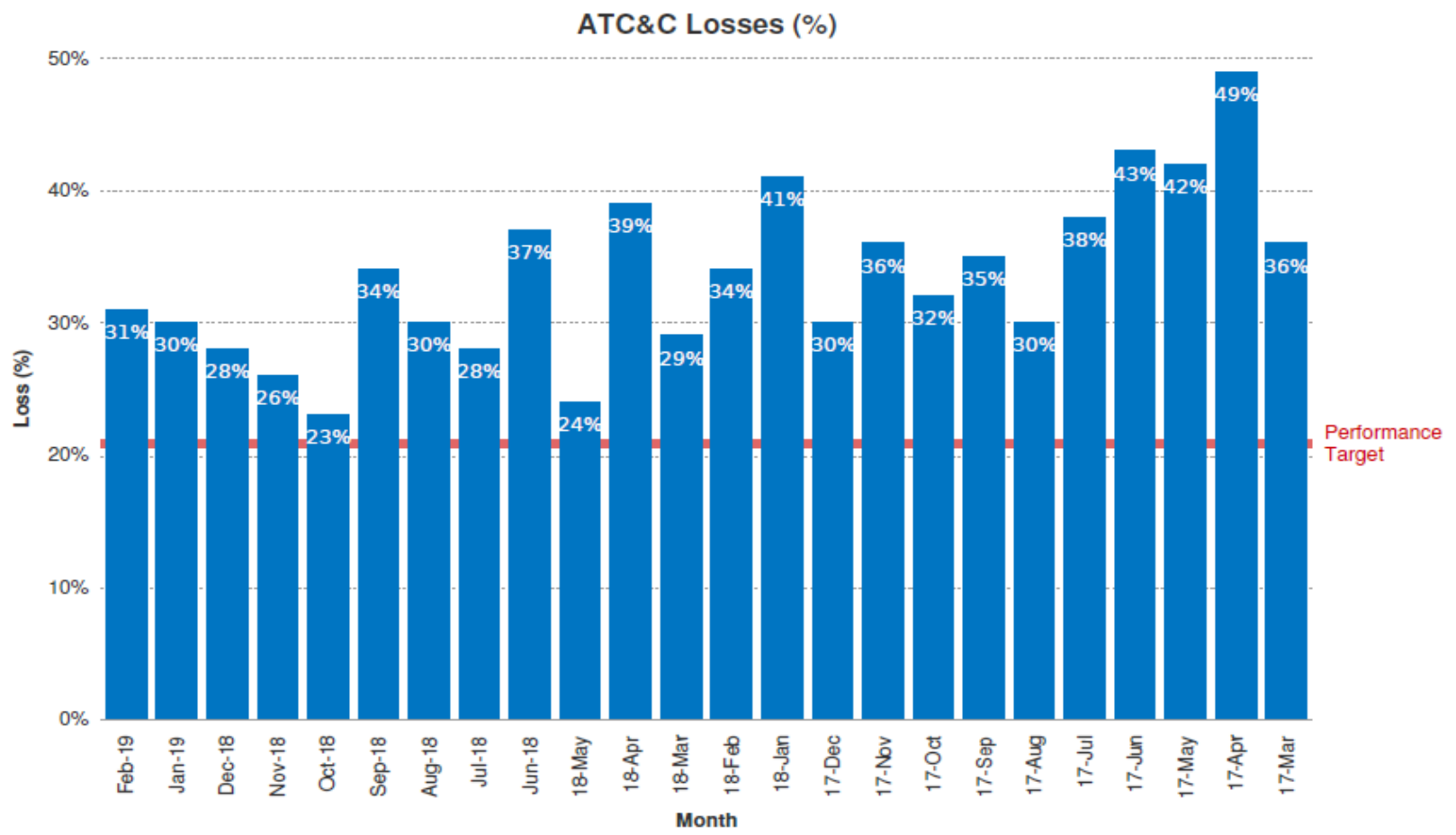

Figure 1: ATC \& C Losses for Ikeja Electricity Distribution Company from March 2017 to February 2019 [8]

Table 1: ATC \& C losses for the eleven (11) distribution companies [8]

\begin{tabular}{|c|c|c|c|c|c|c|c|c|c|c|c|}
\hline No & 1 & 2 & 3 & 4 & 5 & 6 & 7 & 8 & 9 & 10 & 11 \\
\hline DISCO & Abuja & Benin & Eko & Enugu & Ibadan & Ikeja & Jos & Kaduna & Kano & Port Harcourt & Yola \\
\hline $\begin{array}{c}\text { ATC \& C } \\
\text { Losses (\%) }\end{array}$ & 43 & 58 & 31 & 57 & 52 & 31 & 71 & 77 & 47 & 66 & 68 \\
\hline
\end{tabular}

On average the ATC \& $\mathrm{C}$ losses for all the DISCOs in February 2019 are approximately $55 \%$, which is $1 \%$ above the figure reported by World Bank for 2017 [9]. With this percentage, one could see that troubles are looming ahead for the Nigerian power sector if nothing is done urgently. There is therefore urgent need to develop strategies for ATC \& C losses in the Nigerian distribution system.

\section{A. ATC \& C Loss Estimation}

ATC \& C losses are easily calculated using equation (1) [7]: $\operatorname{ATC} \& C \operatorname{Los}(\%)=$

$$
\frac{\text { Energy received -Energy realized }}{\text { Energy received from the transmission }} \times 100
$$

Where;

Energy realized $=$ energy billed $\times$ collection efficiency

$$
\text { Collection Efficiency }=\frac{\text { Amount realized }}{\text { Amount } \text { billed }} \times 100
$$

Provided data are available, ATC \& C losses can easily be estimated using equations (1-3) i.e. if there are no data, losses can never be estimated. If the energy realized equals energy received from transmission then there is no loss in the system. It is impractical to have a system in which no loss exists.

\section{B. ATC \& $\mathrm{C}$ losses classification}

For easy investigations, ATC \& C losses classification is necessary. An attempt must be made to classify the losses to clearly define the source(s)/cause(s) of the losses to be able to design the necessary strategy for mitigation. We should be able to separate technical losses from non-technical losses. Technical losses are losses resulting from the energy dissipated in conductors and distribution equipment [10], while non-technical losses are caused by external factors or load conditions [11].

Further classification of non-technical losses is required for effective mitigation. Losses in this case are consequent on human interference with the system and are therefore very difficult to model due to the high level of unpredictability of human behavior. The simplified classification of ATC \& C losses in a distribution system as given in [12] is as shown in figure 2 . 


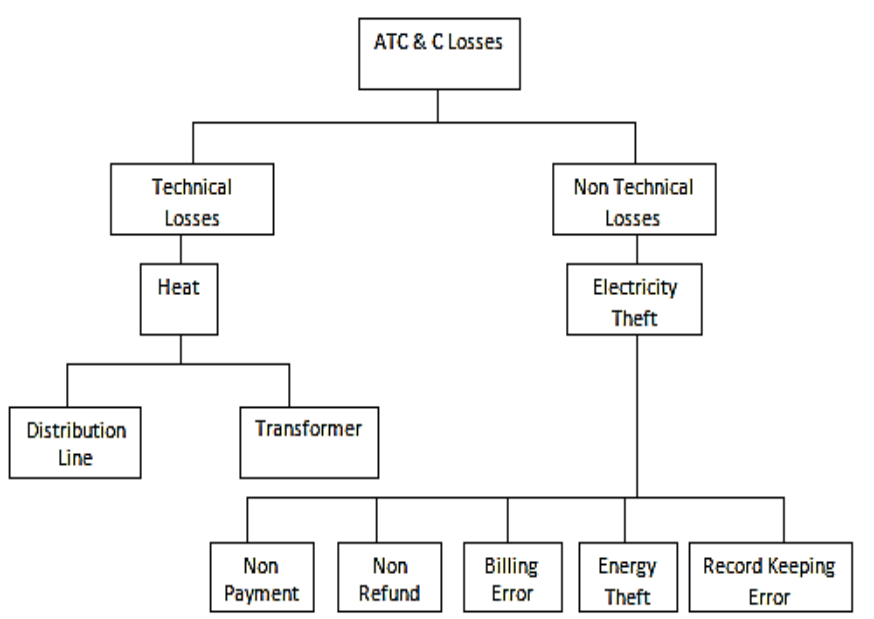

Figure 2: Modified Classification of ATC \& C Losses in



Figure 3: Causes of Non-Technical Losses in Distribution Systems

\section{STRATEGIES FOR MITIGATION OF ATC \& C LOSSES IN THE NIGERIAN DISTRIBUTION SYSTEMS}

To develop strategies for A TC \& $\mathrm{C}$ losses reduction in the Nigerian distribution systems, it is important to have identified the cause(es) of the losses. As a result, the causes of ATC \& C losses shall be presented hand - in- hand with the strategies for mitigation in this section.

For non-technical losses, the causes seem to be the same globally. The causes as presented in [6] for the Metropolitan area Mexico as shown in figure 3 are all evident in the Nigerian distribution system.

\section{Distribution Systems}


Having identified the causes of non-technical losses, the strategies presented in [7] were selectively suggested as strategies that could be used to mitigate non-technical losses in the Nigerian distribution systems. They include:

(i) Provision of smart meters provided with load survey and tamper logging features for all the consumers

(ii) Regular energy auditing and accounting at the feeder level

(iii) Installation of meter outside the premises of the consumers

(iv) Engaging user's association (communities) in theft monitoring

(v) Engaging collection agencies

(vi) Use of electronic payment methods only

For technical losses, the causes include copper resistance, line losses, and iron losses of transformers. These losses are due to the loading and electrical characteristics of the system [13]. Several methods for mitigating technical losses were presented in [14]. Some selected strategies that could benefit the Nigeria distribution system include:

(i) Reconfiguration and Phase Load Balancing.

(ii) Re-conductoring of the networks

(iii) Accurate Distribution Transformers sizing and locating

(iv) Use of Automatic Voltage Booster

(v) Reactive Power Compensation

(vi) Use of Aerial Bunched Cables

(vii) Distributed generation

(viii) High Voltage Distribution System

\section{CONCLUSION}

Nigeria is one of the countries suffering from high ATC \& C losses today after several reforms. Countries like UK, U.S.A., Germany, and India among others once had the same experience. However, they were able to reduce their ATC \& C losses through proper planning, system re-configuration, policy formulation, and compliance as well as collaboration with research institutions. It is on this not that we recommend that policymakers, DISCOs, and research institutions should collaborate towards tackling the excesses of ATC \& C losses in the Nigerian distribution systems.

Conflict of Interest: The authors declare at this moment that there is no conflict of interest.

Acknowledgments: Authors express their appreciation to Covenant University for sponsoring this research work.

\section{REFERENCES}

[1] A. A. Sallam and O. P. Malik, Electric Distribution Systems, Second Edi. Hoboken, New Jersey: JohnWiley \& Sons, Inc., 2019.

[2] M. N. Nwohu, A. S. Mohammed, and U. A. Dodo, 'Methodology for Evaluation of Aggregate Technical, Commercial and Collection ( ATC \& C ) Losses in a Typical Radial Distribution System', Int. J. Res. Stud. Electr. Electron. Eng., vol. 3, no. 2, pp. 1-10, 2017.

[3] A. O. Adedeji, 'Privatisation and Performance of Electricity Distribution Companies in Nigeria', J. Public Adm. Gov., vol. 7, no. 3, pp. 190-203, 2017.

[4] E. Audu, S. O. Paul, and A. Ameh, 'Privatisation of the power sector and poverty of power supply in Nigeria : A policy analysis', Int. J. Dev. Sustain., vol. 6, no. 10, pp. 1218-1231, 2017.

[5] T. L. Alumona, M. O. Nwosu, A. O. Ezechukwu, and J. Chijoke, 'Overview Of Losses And Solutions In Power Transmission Lines', Netw. Complex Syst., vol. 4, no. 8, pp. 24-31, 2014.

[6] Y. Hernández, G. Arroyo-Figueroa, G. Rodríguez, M. Santos, and H. Escobedo, 'Towards a Framework to Detect and Prevent Non-Technical Losses in Power Distribution based on data-mining techniques and Bayesian networks', in 2015 Fourteenth Mexican international Conference on Artificial Intelligence, 2015, pp. 157-161.

[7] M. Kirankumar, K. V Sairam, and R. Santosh, 'Methods to Reduce Aggregate Technical and Commercial ( At \& C ) Losses', vol. 4, no. May, pp. 1501-1505, 2013.

[8] Nigerians Electricity Regulatory Commission, 'ATC \& C Losses', 2019. [Online]. Available: https://nerc.gov.ng/index.php/library/industrystatistics/distribution/119-atc-c-losses. [Accessed: 01-Sep2020].

[9] 'World Bank Project Appraisal Document on Nigeria Electrification Project', 2018.

[10] M. A. Khan, S. Badshah, I. U. Haq, and F. Hussain, 'Measures for reducing transmission and distribution losses of Pakistan', Int. J. Sci. Eng. Res., vol. 4, no. 4, pp. 616-619, 2013.

[11] N. Upreti, R. G. Sunder, N. N. Dalei, and S. Garg, 'Challenges of India $\hat{a} €^{\mathrm{TM}} \mathrm{s}$ power transmission system', Util. Policy, vol. 55, no. November 2017, pp. 129-141, 2018.

[12] A. Otcenasova, A. Bolf, J. Altus, and M. Regula, 'The Influence of Power Quality Indices on Active Power Losses in a Local Distribution Grid', energies, pp. 1-32, 2019.

[13] EPRI, 'Assessment of Transmission and Distribution Losses in New York', 2012.

[14] R. K. Sharma, 'Different Techniques of Loss Minimization in Distribution System', Int. J. Enhance. Res. Sci. Technol. Eng., vol. 2, no. 2, pp. 1-5, 2013. 